\title{
A case study: palliative care for assisted living community residents
}

\begin{abstract}
A case study of an assisted living resident "Harry" demonstrates the positive effects of the implementation of the initial phase of a palliative care program that incorporates an assessment using the Functional Assessment of Chronic Illness Therapy - Spiritual (FACIT-SP). 1 This assessment revealed various spiritual conflicts that he had carried with him most of his life with low scores in areas of feeling connected to others and feeling loved. The interprofessional team led by the Spiritual Director provided individualized care focused on the identified needs leading to the acknowledgement of spiritual wellbeing by Harry. This case study represents a growing population of assisted living residents who are faced with many challenges in overall wellbeing with changes in health and loss experienced throughout life including relocation to a senior living facility. The introduction of Palliative Care or that "extra level of support" they need to manage their conditions with respect to their goals contributes to their wellbeing. Research to establish an evidence-based approach for providing Palliative Care to residents of assisted living communities is essential.
\end{abstract}

Volume I Issue 7 - 2017

\author{
Rebecca Bass, ${ }^{2}$ Hutch Walch, ${ }^{2}$ Katie \\ Westberg, ${ }^{2}$ Phyllis Gaspar' \\ 'National Director of Research and Development, The \\ Goodman Group, USA \\ ${ }^{2}$ The Goodman Group, USA
}

\begin{abstract}
Correspondence: Phyllis M Gaspar, National Director of Research and Development, The Goodman Group, 1107 Hazeltine Boulevard, Suite 200, Chaska MN 55318, Tel 419-2805252; Email Phyllis.gaspar@thegoodmangroup.com
\end{abstract}

Received: December 06, 2017 | Published: December 21, 2017

Keywords: palliative care, assisted living

Abbreviations: TGG, the goodman group; FACIT-SP, functional assessment of chronic illness therapy - spiritual; NAHC, national association for home care \& hospice; HFMA, hospice financial managers association

\section{Introduction}

The Goodman Group combines 50 years of senior living and health care experience with leading-edge innovation, exceptional design and compassionate care located in eight states. The Goodman Group offers independent, assisted living, memory care and long-term care communities. Optimal wellbeing of the resident, comprised as the integration of the mind, body and spirit, is the core of the care and services provided. Based on this model TGG recognized the need to establish a Palliative Care program for residents of assisted living communities. An interprofessional team was charged with the development of a program. The first step was to determine a definition of Palliative Care that would serve as a basis for the development of the program. The National Consensus Project 2013 Definition of Palliative Care (National Association for Home Care \& Hospice (NAHC) Home Care \& Hospice Financial Managers Association (HHFMA) Palliative Care 2013) ${ }^{2}$ with inclusion of several characteristics from The Center to Advance Palliative $\mathrm{Care}^{3}$ was integrated into the definition. The definition with adaptations (italics) follows:

Palliative care is both a philosophy of care and an organized, highly structured system for delivering care. Palliative care encompasses the whole person. It expands traditional disease-model medical treatments to include the goals of enhancing quality of life for patient and family at any stage of the disease, through the provision of relief from the symptoms, pain and stress of an illness, optimizing function, helping with decision-making and providing opportunities for personal growth. As such, it can be delivered concurrently with life-prolonging care as an extra layer of support, as the main focus of care, or in the transition to end of life care.
A guideline for addressing the spiritual wellbeing of the residents has been implemented and is the initial phase of the Palliative Care program. The guideline incorporates the administration of the Functional Assessment of Chronic Illness Therapy-Spiritual (FACITSP) by the community's Spiritual Director on admission, yearly, with a change in condition and through referral from nursing, housekeeping, dining and other teams. FACIT-SP was developed to describe spiritual wellbeing and is not limited to any religious or spiritual tradition. The administration of the instrument is viewed as an interventional assessment. The 1:1 interview serves as an opportunity for the resident to reflect and share their strengths and concerns related to their spirituality. An individualized plan focused on development of strengths and addressing areas of needs/issues/concerns identified through the administration of the scale is then implemented and integrated with the interprofessional plan of care. ${ }^{4}$

\section{Case presentation}

Harry was a new resident of the assisted living community when the Spiritual Director administered the FACIT-SP in a private interview. This assessment revealed various spiritual conflicts that he had carried with him most of his life, which he had dealt with and worked on to improve over the years. The assessment identified low scores in areas of feeling connected to others and feeling loved. ${ }^{5}$ The low scores were attributed to childhood physical and emotional abuse, struggles with a life of psychological issues, a disconnection with his faith and religious practices, and now symptoms of Parkinson's that had weakened his body. One aspect of the disease that was particularly distressing was his weak voice affecting his ability to sing, something he had done professionally after retirement. He was currently experiencing increasing debilitation with uncontrolled tremors and frequent falls. The plan to address the spiritual concerns included weekly 1:1 visits working on the identified issues, as well as collaboration with the health care team to address health issues especially improvement of his voice. 
Harry had shared that he had a very successful career with NASA in public relations during the time of some exciting advances. He had the privilege of having meetings with United States Presidents and other celebrities along the way. The Spiritual Director recognized the importance of these experiences and encouraged the resident to write his "memoir" as he continued to sort out the many events of his life, the highs and lows. He loved this idea and in a short time had hand typed out numerous chapters. He shared that he had the hope that in the future proceeds from his book proceeds would go toward an organization helping abused children. Harry also reignited his faith through the assistance of the Spiritual Director. His faith has provided the strength he has needed to make it through difficult times he has since encountered.

Over the past 6 months Harry's symptoms have gotten progressively worse. He began to experience more falls with subsequent trips to the Emergency Room. He is now wheel chair bound and can no longer type his memoir. He is circumspect about his prospects, realizing that he will continue to decline. A volunteer meets with him twice a week to which he is dictating his remaining chapters of his memoir. He has handed the recordings of his singing over to a friend who is making CD's for him to give as gifts this Christmas. Photos of NASA launches, Frank Sinatra signed posters and other meaningful items line the walls of his apartment, which he calls his "sanctuary".

The interprofessional team discussed the benefits that Harry would receive through Hospice. The Spiritual Director raised the conversation with Harry regarding the possible use of Hospice care with the response of many-shocked that is was mentioned as his notation of hospice meant that "he would die soon". After an explanation of the services Hospice could provide, some thinking time and several more discussions Harry decided to have a Hospice consult. He enrolled and has been in hospice care for several months now. His symptoms have improved and he loves the visits from the $\mathrm{RN}$ and other hospice staff who augment his care.

Harry and the Spiritual Director meet regularly and talked about his faith in light of his disease progression. He has established what has been important in his life and not so important. He does realize that his disease will take his life and is better prepared for whatever comes next. Harry has stated, "You know, it's really not about where I've been, or what I've done or who I've met. It's about who I am in the eyes of God."

\section{Discussion}

This case study demonstrates, even though only the initial phase of implementation has been completed, that a Palliative Care program for the residents of assisted living communities within TGG's senior living and health care managed communities makes a difference in the quality of life experienced. ${ }^{4}$ The definition of Palliative Care that guides the development of the program indicates that "goals of enhancing quality of life for patient and family at any stage of the disease, through the provision of relief from the symptoms, pain and stress of an illness, optimizing function, helping with decisionmaking and providing opportunities for personal growth.” The case study of Harry demonstrates how addressing the spirit improved his quality of life and provides the impetus to provide Palliative Care to every assisted living resident. Research to establish an evidence-based approach for providing Palliative Care to residents of assisted living communities is essential.

\section{Acknowledgements}

The authors want to acknowledge the resident who allowed his story to be shared for the benefit of other residents and as a "call to action" for the development of a comprehensive evidence based Palliative Care program for assisted living residents.

\section{Conflicts of interest}

The author declares no conflict of interest.

\section{Patient consent form}

Resident consent is available on file at TGG corporate office.

\section{References}

1. http://www.facit.org/FACITOrg

2. https://www.nahc.org/assets/1/7/NAHCPCWhitePaper.pdf

3. CAPC. Improving care for people with serious illness through innovative payer-provider partnerships: a palliative care Toolkit and resource guide. USA: Springer; 2014. p. 1-40.

4. Walch H, Gaspar PM, Westberg K. A spiritual well-being guideline revitalizes assisted living residents: there are a million stories to tell and there are just as many interventions to explore. HealthCare Chaplaincy's Caring for the Human Spirit Magazine. 2017;4(1):20-21.

5. Munoz AR, Salsman JM, Stein KD, et al. Reference values of the functional assessment of chronic illness therapy-spiritual well-being: a report from the American cancer society's studies of cancer survivors. Cancer. 2015;121(11):1838-1844. 